УДК $811.113 .5+81^{\prime} 28+81^{\prime} 374$

\title{
А.Н. Ливанова
}

Санкт-Петербургский государственный университет

\author{
Н. В. Сафонова \\ Брянский государственный университет \\ им. академика И. Г. Петровского
}

ПОСЛЕ ИВАРА ОСЕНА:

\section{СТАНОВЛЕНИЕ НОРВЕЖСКОЙ ДИАЛЕКТОЛОГИИ В КОНЦЕ ХІХ — НАЧАЛЕ ХХ СТОЛЕТИЙ}

Положение диалектов в Норвегии своеобразно: диалектная речь широко распространена, в том числе в СМИ, и престижна. Изучение диалектов традиционно является одной из наиболее популярных лингвистических дисциплин, имена наиболее значительных диалектологов у всех на слуху. Такой интерес к диалектологии объясняется целым рядом причин, как собственно лингвистических, так и экстралингвистических (особенности норвежской истории, в частности относительно недавнее обретение страной независимости). Пробуждение интереса к диалектам как проявление национальной идентичности можно считать заслугой лингвиста-самоучки Ивара Осена, собравшего и сделавшего достоянием общественности в виде как грамматических, так и лексикографических трудов обширный диалектный материал. Однако подлинно научное изучение диалектного материала, когда его сбор и анализ постепенно перешли в руки профессионалов, началось уже после Осена. Но если вкладу Осена в изучение норвежских диалектов посвящена обширная литература, о целом ряде профессиональных норвежских диалектологов написано мало, а в нашей стране они практически неизвестны. Именно периоду становления научной диалектологии в Норвегии в конце XIX - начале XX в. и основным диалектологам этого периода посвящена статья. Дается характеристика деятельности исследователей, стоявших у истоков научной диалектологии, - Ханса Росса, Юхана Сторма и Амюнна Б. Ларсена. Рассматривается вопрос о состоянии изучения фонетики, лексики, морфологии и синтаксиса норвежских диалектов в исследуемый период. Дается анализ наиболее часто использовавшихся в то время методов исследования норвежских диалектов.

Ключевые слова: диалект, диалектная лексикография, диалектная география, история диалектологии, диалектолог. 
Aleksandra Livanova

St. Petersburg State University

Natalia Safonova

Ivan Petrovsky Bryansk State University

AFTER IVAR AASEN:

FORMATION OF NORWEGIAN DIALECTOLOGY

IN THE END OF $19^{\text {th }}-$ BEGINNING OF $20^{\text {th }}$ CENTURY

Dialects in Norway are widely used, and attitude towards dialect speech is rather positive. Dialects are spoken in public contexts and in the media. This situation should be seen in connection with the peculiarities of Norwegian history (late independence acquisition, among other causes). In this situation it is not surprising that dialect research is highly appreciated, and names of the prominent dialectologists are known to average Norwegians. This is certainly true as for Ivar Aasen, the amateur linguist and lexicographer who devoted all his life to preserving dialects and who assembled on the base of dialect patterns one of the two official written versions of the Norwegian language. He was one of the key figures in the formation of Norwegian national identity, and his life and work have been described in a lot of books and articles. It is though during the next period, in the end of the $19^{\text {th }}-$ beginning of the $20^{\text {th }}$ century, that really scientific research in Norwegian dialects starts. Regretfully, the prominent Norwegian dialectologists of this time and their achievements are not as well-known as I. Aasen, and Russian researches are practically unfamiliar with them. The article is devoted to this interesting period in the evolution of Norwegian dialectology. It contains characteristics of the three leading researchers of this time, Hans Ross, Johan Storm and Amund B. Larsen. The issue of progress in studying phonetics, morphology and syntax of Norwegian dialects is touched upon, too. Some consideration is given to the matter of the most usual methods of dialect studies of the time.

Keywords: dialect, dialect lexicography, dialect geography, history of dialectology, dialectologist.

Датское владычество (1537-1814) не способствовало изучению диалектов в Норвегии. Не только диалекты, но и городские говоры, развившиеся на базе языка датских чиновников и служителей церкви, но сохранявшие особенности норвежского произношения, считались провинциальными и вызывали в лучшем случае снисходительное отношение. Подъем национального самосознания, наблюдавшийся в стране с конца XVIII в. и приведший к отделению от Дании и созданию собственной конституции, означал коренной переворот и в отношении к родному языку. Особенно важной в деле изучения народных говоров оказалась деятельность любителя-самоучки Ивара Осена (Ivar Andreas Aasen, 1813-1896), пришедшаяся на середину XIX в. Главной заслугой И. Осена в диалектологии можно считать проделанную им колоссальную работу 
по сбору диалектного материала и его популяризации в публикациях. Можно с уверенностью сказать, что во многом благодаря именно И.Осену в Норвегии до сих пор наблюдается огромный интерес как к диалектной речи, так и к диалектологии. Однако если фигуре И.Осена и его заслугам посвящена обширная литература, то деятельность его преемников в период конца XIX - начала XX столетия незаслуженно остается в тени, хотя именно в это время были заложены основы подлинно научного исследования норвежских диалектов.

Систематическое изучение диалектов в Норвегии началось с 80-х годов XIX в. Теперь родные говоры вызывают интерес не только как часть поисков национальной идентичности и как аргумент в языковой политике, но и как объект лингвистических штудий. На начало этого периода приходится деятельность многих крупных норвежских диалектологов, таких как Х. Росс (1833-1914), Ю.Сторм (1836-1920), А.Б. Ларсен (1849-1928) и некоторых других. Ими были созданы выдающиеся диалектологические труды, составляющие и по сей день гордость норвежской диалектологии. Они продолжили работу, основные направления которой были намечены И. Осеном в его трудах, и способствовали дальнейшему росту интереса к изучению диалектов как среди языковедов, так и у широкой публики.

Непосредственным преемником дела И. Осена был Ханс Матиас Элисеус Росc (Hans Matthias Elisæus Ross), родившийся в Мандале (Западная Норвегия), дальний потомок переселенцев из Шотландии. В отличие от И. Осена Х. Росс получил хорошее богословское образование, знал немецкий и английский языки, иврит, а в Великобритании изучал фонетику [https://nbl.snl.no/Hans_Ross]. Еще обучаясь в кафедральном училище в Кристиансанне, Х.Росс от преподавателя услышал о том, что, по мнению И. Осена, древний норвежский язык все еще существует в Норвегии в форме диалектов. Это произвело на Х. Росса колоссальное впечатление, и он навсегда сохранил глубочайшее уважение к Ивару Осену и его деятельности. В 1857 г. Ханс Росс познакомился с Осеном лично, с тех пор их встречи носили регулярный характер. Х. Росс стал помогать И.Осену собирать диалектную лексику для словаря, а после выхода второго издания словаря И. Осена (1873) приступил к работе над своим словарем. В 1877 г. Х. Росс получил стипендию на из- 
учение диалектов и с этого времени полностью посвятил себя лексикографии. Словарь был опубликован им в 1895 г. под названием Norsk Ordbog. Tilloeg til "Norsk Ordbog” af Ivar Aasen. Подзаголовок издания - «Приложение к словарю И.Осена» - свидетельствует о том, что Росс, с одной стороны, считал себя последователем Осена, а с другой - весьма скромно оценивал собственный вклад в изучение диалектов. Однако Х. Росс на этом не остановился. Он продолжил сбор и публикацию диалектной лексики в виде приложений к словарю, публиковавшихся в период 1902-1913 гг. Работа Х. Росса включала около 40000 диалектных слов - это больше, чем в словаре И.Осена. К тому же Х. Росс включал в словарь и сложные слова, они составили значительную часть лексикона, в словаре же И. Осена их было немного. Важно и то, что в словаре Х. Росса хорошо представлены восточные диалекты Норвегии, что свидетельствует о научной непредвзятости автора, ведь Осен описал их в своем словаре весьма схематично, руководствуясь собственным национально-романтическим представлением об их меньшей исконности по сравнению с западными, сильнее отличавшимися от датского языка и сохранявшими больше архаичных черт.

Еще одним крупным произведением Х. Росса явился обзор норвежских диалектов, представленный им в работе Norske bygdemaal (1905-1909). Этот обширный труд, состоящий из 18 разделов, представляет собой ряд более или менее подробных описаний практически всех диалектов Норвегии. В этой работе, как и в своем словаре, Х. Росс больше внимания уделил тем районам страны, которые были мало исследованы И.Осеном. Подробнейшее описание диалектов Западного Телемарка, сделанное Х.Россом, до сих пор считается никем не превзойденным [Beito, 1973, s. 15]. Поскольку по образованию Х. Росс был фонетистом, основное место в его работе занимает описание фонетических систем норвежских говоров. При записи диалектного материала он пользовался новой тогда (и очень сложной) фонетической транскрипцией, разработанной профессором Ю.Стормом. Вопросам же морфологии $\mathrm{X}$. Росс уделял меньше внимания, что было, впрочем, характерно для того времени. Х. Росс фиксировал также идиоматические выражения, пословицы и поговорки. Эта работа, фактически труд всей жизни Х. Росса, по праву считается необходимой основой для изучения норвежских диалектов. 
Титанический труд Х.Росса не остался без внимания. В 80-е годы XIX в. возникла идея дать Х. Россу должность «профессора норвежской народной речи» (professor i norsk folkemål), за что проголосовало большинство в стортинге. Однако университетские профессора, в том числе языковед и фольклорист Софус Бугге и фонетист и диалектолог Юхан Сторм, транскрипцией которого добросовестно пользовался Х.Росс, воспротивились этому, поскольку Х. Росс поддерживал и использовал лансмол и был одним из основателей в 1868 г. союза в его поддержку (Det norske Samlaget) [https://nbl.snl.no/Hans_Ross]. В наши дни, очевидно, это говорило бы только в пользу X. Росса!

При том что по уровню и широте образованности Х. Росс намного превосходил Ивара Осена, теоретическую базу его научных воззрений составлял младограмматизм с его романтическими представлениями о «духе» языка и его исторических корнях, которые и следовало обнаруживать при изучении диалектного материала.

Тем не менее именно И. Осеном, Х. Россом, а также практически забытым лексикографом Стейнаром Шёттом (Steinar Schjøtt, 18441920) (его работа, как и работа диалектолога-любителя Кристиана Видстена (Christian Vidsteen, 1832-1915), заслуживает отдельного изложения и анализа) была создана та лексикографическая база и те принципы, на которых построено гигантское здание так называемого «Норвежского словаря» - Norsk Ordbok [Norsk Ordbok], выходившего с подзаголовком «Словарь норвежской народной речи и новонорвежского письменного языка» - Ordbok over det norske folkemålet og det nynorske skriftmålet. Работа над ним шла с перерывами с 1950 г., последний том вышел 9 марта 2016 г. В этот словарь включены все зафиксированные норвежскими лексикографами диалектные варианты слов, всего 330000 лемм [Norsk Ordbok].

Как уже было сказано, основной задачей и основным достижением данного периода была организация систематического изучения родных говоров. Сформулировал же и всесторонне обосновал эту задачу Юхан Фредрик Бреда Сторм (Johan Storm, 1836-1920), профессор английской и романской филологии университета в Осло. Он был чрезвычайно талантливым фонетистом (современники называли его «норвежским профессором Хиггинсом» [Juul, 1999, s.49]), и именно занятия фонетикой привели его к изучению 
диалектов. Он же первым из норвежских ученых применил новейший на тот момент в диалектологии метод немецкого исследователя Георга Венкера (Georg Wenker, 1852-1911)․․ Ю. Сторм разработал в 1882 г. два списка слов для изучения исторической фонетики: один, более краткий - из 300 слов, который Сторм разослал по всей стране, и другой, состоявший из 4000 слов, напечатанный под названием Norsk Ordliste til Lydlaeren. Позже Сторм переработал эти списки, в результате появился знаменитый «краткий список слов» Ю. Сторма (Kortere Ordliste med Forklaring af Lydskriften, 1884), который содержал 2000 слов, предназначавшихся для изучения не только фонетики, но и морфологии норвежских диалектов. Продуманность списка позволила ему стать рабочим инструментом не для одного поколения диалектологов в Норвегии.

Использовав в качестве образца шведскую транскрипцию Юхана Августа Лунделя (Johan August Lundell, 1851-1940) и описав звуки почти всех норвежских диалектов, Ю.Сторм в работе Norsk Lydskrift med Omrids af Fonetiken, опубликованной частями в основанном при его же участии журнале Norvegia, в 1884 г. (основная часть - описание диалектов, s. 19-132) и 1908 г. (собственно система транскрипции, s. 10-179) [Storm, 1908], представил систему фонетической транскрипции Norvegia, как нельзя более точно описывающую звуки норвежских диалектов. О подробности системы Ю. Сторма может говорить тот факт, что в ней, например, предлагается 11 знаков для описания Fremre runde Vokaler и 12 - для описания Bagre runde Vokaler (передних и задних огубленных гласных соответственно) [Storm, 1908, s. 178-179]. Этой транскрипцией до сих пор пользуются в практике преподавания скандинавистики в норвежских университетах и при записи норвежских диалектных текстов.

Высоко оценивается последующими поколениями норвежских диалектологов организаторская деятельность Ю.Сторма. При его участии начал издаваться журнал Norvegia, задуманный как орган

${ }^{1}$ Сам Венкер впервые применил его в 1876 г. Анкетирование по Г. Венкеру было совершенно новым словом в диалектологической науке того времени, о том, насколько новым, может свидетельствовать тот факт, что исследователи диалектов немецкого языка с конца прошлого века вновь взяли на вооружение его метод и материалы. См. об этом: [Кахро, 2006, с. 3]. Подробнее о методе Г. Венкера и его последователей см. также: [Строева, 1985, с. 37-43]. 
«Объединения по изучению норвежских диалектов и народных обычаев» (Foreningen for norske dialekter og traditioner), созданного в 1881 г. ведущими норвежскими диалектологами. Во введении к 1-му тому Norvegia Сторм предложил программу будущих исследований народных говоров. Он ратовал за строго систематическое изучение говоров: должны изучаться все особенности диалектов, следует также изучать отдельные диалекты и диалектные группы, взаимоотношение диалектов и их историческое развитие. Исследование должно вестись не одиночками-любителями, а профессиональными диалектологами по единой программе, причем изучаться должны все без исключения диалекты, как сельские, так и городские [Hansen, 2010, s.43]. Последний тезис очень важен. Как указывалось выше, адепты младограмматизма отдавали предпочтение сельским говорам как «более исконным», и это, собственно, совпадало с социолингвистической позицией сторонников лансмола еще долгие годы. Характерна следующая цитата из работы, вышедшей на три четверти столетия позже опубликования программы Ю. Сторма: "Språkleg var byen aldri norsk. <...> Det dansk-norske målet var overklassemålet. <...> Det er bygda som er berar av den norske målarven som ho er berar av det aller meste av vår norske kulturarv" - «В языковом отношении город никогда не был норвежским. <...> Датско-норвежский служил языком высших слоев общества. <...> Именно сельские говоры являются носителями норвежского языкового наследия, как и большей части нашего норвежского культурного наследия» [Hovdhaugen, 1956, s. 3]. Сторонники риксмола, напротив, выступали за постепенную норвегизацию языка образованных слоев городского населения.

Сторм в этом отношении занимал сугубо научную, непредвзятую позицию, выступив в ряде статей с критикой как лансмолистов, так и риксмолистов [https://snl.no/Johan_Storm]. Еще до создания журнала Norvegia неутомимый Ю. Сторм, после принятия стортингом 12 мая 1885 г. 78 голосами против 31 решения о придании лансмолу статуса официального языка наравне с общепринятым на тот момент датско-норвежским, т. е. риксмолом, опубликовал в мае-июне 1886 г. ряд статей в газете Morgenbladet, которые позже были им собраны и выпущены отдельной книгой [Storm, 1888]. В предисловии к работе Сторм пишет: “Det forekom mig, at det førtes saa megen løs og usikker Tale om 'Landsmaalet', som om det 
var ét eneste Sprog med én bestemt Form, uden nærmere Undersøgelse af, hvorledes det egentlig forholdt sig med denne Enhed" - «Мне представилось, что ведется очень много несвязных и неточных речей о “лансмоле”, как если бы это был единый язык с одной определенной формой, и при этом не проводится тщательных исследований того, как же именно обстоят дела с этой единицей» [Storm, 1888]. Он приходит к выводу: "et Sprog med saa store indbyrdes Afvigelser er intet Landsprog, men blot en Samling Dialekter" - «Язык со столь значительными расхождениями <между своими формами> является не языком страны, но всего лишь собранием диалектов» [Storm, 1888].

Среди многочисленных учеников профессора Сторма самым талантливым и известным, а также следовавшим линии учителя изучать диалекты беспристрастно, с научной точки зрения - был Амюнн Б. Ларсен (Amund Bredesen Larsen, 1849-1928). Его первая работа Oplysninger om Dialekter $i$ Selbu og Guldalen (1881) была охарактеризована Ю. Стормом как «первая соответствующая требованиям нового времени научная работа об одном норвежском диалекте» (цит. по: [Hoff, 1968, s. 423]).

В то время, когда в европейских странах только начинали заниматься вопросами лингвогеографии, А. Б. Ларсен уже применил разработанный им метод изучения диалектов с географической точки зрения при описании тронхеймских диалектов (Oversigt over de trondhjemske Dialekters Sloegtskabsforhold, 1886) и пользовался им во всех своих последующих работах. Будучи в первую очередь фонетистом, Ларсен учитывал языковые явления в их взаимосвязях. Это проявилось и в его первой работе, и в докторской диссертации Lydloeren $i$ den solørske Dialekt isør $i$ dens Forhold til Oldsproget (1894), посвященной описанию родного диалекта А.Б.Ларсена (она вплоть до наших дней является образцом исследования для норвежских диалектологов (см. об этом: [Hansen, 2010, s.43])), и в труде Sognemålene (1926).

В фонетике А. Б. Ларсен стремился обобщить характеристики отдельных звуков в систематическое описание языковых законов и тенденций, таких как слоговое равновесие, выравнивание гласных, палатализация дентальных согласных и другие. Системные описания фонетических особенностей норвежских диалектов, выполненные Ларсеном, приближались к современному фоноло- 
гическому методу. Ряд работ ученый посвятил проблемам пограничных диалектов, подчеркивая трудность проведения разграничительной линии при описании постепенности перехода одних диалектов в другие (Om de norske dialekters forhold til nabosprogene, 1896, Overgangsmaalene mellem østnorsk og vestnorsk, 1915 и др.). Диалекты он изучал на местах, объездив почти всю страну. В 1892 г. он опубликовал первую норвежскую диалектную карту Oversigtskart over visse dialektfonomeners udbredelse i Kristiansands stift, а в 1897 г. выпустил работу Oversigt over de norske bygdemaal («Обзор норвежских сельских говоров»), в которой рассматриваются не только фонетика, но и морфология диалектов, что было для своего времени новым.

Занимался Амюнн Ларсен и городскими говорами, с целью изучения которых в 1903 г. было создано общество Bymaalslaget. По инициативе этого общества Ларсен изучал говор столицы (Kristiania bymål, 1907, с характерным подзаголовком Vulgorsproget med henblik på den utvungne dagligtale - «Вульгарный язык с учетом непринужденной повседневной речи»), затем исследовал диалекты Бергена (Bergens bymål, 1912, совместно с Г. Штольцем, G. Stoltz) и Ставангера (Stavangers bymål, 1925, совместно с М. Бернтсеном, M.Berntsen). Эти работы являются пионерскими не только для Норвегии, но и для всей Скандинавии. Основное место в них занимает описание современного на тот момент состояния языка (словарный состав и идиоматика), а также социальных отношений в той среде, где пользовались соответствующим говором. Эти книги послужили образцами для будущих исследований такого рода. Последней большой работой Ларсена стало описание диалектов местности Согн, представленное в виде таблиц (Sognemålene, 1922-1926). В этой работе он вплотную подошел к тем идеям, которые чуть позже сформулировала и обосновала фонология. Так, он придавал основополагающее значение понятию оппозиции, а также пытался собрать воедино под общим знаком варианты звука.

К сожалению, хотя Юхан Сторм широко использовал в своей работе новейшие доказательные методы, а Амюнном Ларсеном был успешно применен новый принцип исследования диалектов с учетом их географического распространения, для последующих исследований в области норвежской диалектологии вплоть до середины прошлого века, на который пришлась деятельность 
выдающегося норвежского диалектолога Халлфрид Кристиансен (Hallfrid Christiansen, 1886-1964), поставившей изучение диалектов на современную научную основу, и даже позже более свойственна приверженность младограмматическим принципам. Это можно объяснить целым рядом причин: неготовностью современников Сторма и Ларсена принять столь радикально новые методы и взгляды, влиянием шведской диалектологической школы (упомянутый выше Ю. Лундель, а также А.Нурен), авторитетом, которым пользовался Мариус Хэгстад (Marius Hægstad, 1850-1927)2. В современных говорах его интересовали лишь реликты древненорвежского состояния. Его взгляды и научная плодовитость на многие годы предопределили развитие преимущественно исторического направления в норвежской диалектологии (см.: [Beito, 1973, s.16]). К тому же в Норвегии, пребывавшей в поиске собственной национальной идентичности, наука о языке всегда составляла часть языковой политики, направленной на утверждение преемственности с предшествовавшим датскому периодом.

Тем не менее усилия как Х. Росса, так и Ю. Сторма и А. Б. Ларсена оказались не напрасными. Именно эти три имени упоминаются в обобщающем современном труде, посвященном истории скандинавского языкознания [Hovdhaugen et al., 2000, s. 151 et seq.]. С уверенностью можно сказать, что вся норвежская диалектология после Ивара Осена покоится на трех китах - лексикографии Ханса Росса, фонетической транскрипции Юхана Сторма и системных описаниях Амюнна Б. Ларсена, составивших прочную лексикографическую и научную базу для последующего всестороннего изучения норвежских диалектов.

\section{ЛИТЕРАТУРА}

Кахро Н. М. Синтаксические особенности алеманнских диалектов Швейцарии: автореф. дис. ... канд. филол. наук. СПб.: Изд-во СПбГУ, 2006. С. 3. Строева Т. В. Немецкая диалектология. Л.: Изд-во ЛГУ, 1985. С. 37-43.

Beito O.T. Utsyn over målføregransking // Frå norsk målføregransking. Oslo: Universitetsforlaget, 1973. S. 11-23.

Hanssen E. Dialekter i Norge. Bergen: Fagbokforlaget, 2010. 211 s.

${ }^{2}$ Мариус Хэгстад - общественный деятель, сторонник лансмола, с 1899 г. и до конца жизни профессор норвежского языка и диалектов в университете Осло. 
Hoff I. Norwegische Mundartforschung // Germanische Dialektologie. Festschrift

für W. Mitzka zum 80. Geburtstag. Wiesbaden: Steiner, 1968. S. 398-458.

Hovdhaugen E. Målreising og bondereising. S.l: Noregs mållag, 1956. 3 s.

Hovdhaugen E. et al. The History of Linguistics in Northern Countries. Helsinki: Societas Scientiarum Fennica, 2000. $418 \mathrm{~s}$.

Juul A. Nordmændenes Professor Higgins // Uddannelseshistorie. Odense: Syddansk Universitetsforlag, 1999. S. 49-74.

Norsk Ordbok. URL: http://www.nob-ordbok.uio.no/info/NOB_1_Innleiing. html (дата обращения: 18.01.2016).

Simonsen H. G. Johan Storm. URL: https://snl.no/Johan_Storm (дата обращения: 11.11.2015).

Storm J. Norsk Lydskrift med Omrids af Fonetiken // Norvegia. Bind I. Kristiania, 1908. S. 10-179.

Storm J. Det nynorske Landsmaal. København: Gyldendalske Boghandels Forlag (F. Hegel \& Søn), 1888. $116 \mathrm{~s}$.

Venås Kj. Hans Ross. URL: https://nbl.snl.no/Hans_Ross (дата обращения: 14.12.2015).

\section{REFERENCES}

Kakhro N.M. Sintaksicheskie osobennosti alemannskikh dialektov Shveitsarii. Avtoref. dis. kand. filol. nauk [Syntactic features of Alemannic dialects in Switzerland. Thesis of PhD diss.]. St. Petersburg, St. Petersburg Univ. Press, 2006, p. 3. (In Russian)

Stroeva T. V. Nemetskaia dialektologiia [German dialectology]. Leningrad, Leningrad Univ. Press, 1985, pp.37-43. (In Russian)

Beito O.T. Utsyn over målføregransking [Survey of Dialect Research]. Frå norsk målføregransking [Some acpects of Norwegian research in Dialectology]. Oslo, Universitetsforlaget, 1973, pp. 11-23.

Hanssen E. Dialekter i Norge [Dialects in Norway]. Bergen, Fagbokforlaget, 2010. $211 \mathrm{p}$.

Hoff I. Norwegische Mundartforschung [Norwegian research in Dialectology]. Germanische Dialektologie. Festschrift für W. Mitzka zum 80. Geburtstag [Germanic Dialectology. Festschrift for W. Mitzka on the Occasion of his 80th Birthday]. Wiesbaden, Steiner, 1968, pp.398-458.

Hovdhaugen E. Målreising og bondereising [Language movement and farmer movement]. S.1., 1956, p. 3.

Hovdhaugen et al. The History of Linguistics in Northern Countries. Helsinki, Societas Scientiarum Fennica, 2000. 418 p.

Juul A. Nordmændenes Professor Higgins [Norwegians' Professor Higgins]. Uddannelseshistorie [History of Education]. Odense, Syddansk Universitetsforlag 1999, pp. 49-74.

Norsk Ordbok [Norwegian Dictionary]. Available at: https://www.nob- ordbok.uio. no /info/ NOB_1_Innleiing. html (accessed: 18.01.2016). 
Simonsen H. G. Johan Storm. Available at: https://snl.no/Johan_Storm (accessed: 11.11.2015).

Storm J. Norsk Lydskrift med Omrids af Fonetiken [Norwegian Sound Notation with the Outline of Phonetics]. Norvegia. Bind I. Kristiania, 1908, pp. 10-179.

Storm J. Det nynorske Landsmaal [The New-Norwegian landsmaal ("country language”)]. København, Gyldendalske Boghandels Forlag (F.Hegel \& Søn), $1888.116 \mathrm{p}$.

Venås Kj. Hans Ross. Available at: https://nbl.snl.no/Hans_Ross (accessed: 14.12.2015).

\title{
Ливанова Александра Николаевна
}

кандидат филологических наук, доцент кафедры скандинавской

и нидерландской филологии, филологический факультет,

Санкт-Петербургский государственный университет.

Российская Федерация, 199034, Санкт-Петербург,

Университетская наб., д. 7-9

E-mail: a.livanova@spbu.ru

\author{
Aleksandra Livanova \\ $\mathrm{PhD}$ in Philology, Associate Professor, \\ Department of the Scandinavian and Dutch Philology, \\ Faculty of Philology, St. Petersburg State University. \\ 7-9, Universitetskaya nab., St. Petersburg, 199034, Russia \\ E-mail: a.livanova@spbu.ru
}

\section{Сафонова Наталья Васильевна}

кандидат филологических наук,

доцент кафедры немецкого языка,

факультет иностранных языков,

Брянский государственный университет

им. академика И. Г. Петровского.

Российская Федерация, 241036, Брянск, ул. Бежицкая, д. 14

E-mail: saphonchik@mail.ru

\section{Natalia Safonova}

$\mathrm{PhD}$ in Philology, Associate Professor,

Department of the German language,

Faculty of Foreign languages,

Ivan Petrovsky Bryansk State University.

14, Bezhitskaya Street, Bryansk, 241036, Russia

E-mail: saphonchik@mail.ru 